\title{
BMJ Open Qualitative investigation of patients' experience of a glaucoma virtual clinic in a specialist ophthalmic hospital in London, UK
}

\author{
Aachal Kotecha, Karen Bonstein, Richard Cable, Jocelyn Cammack, Jane Clipston, \\ Paul Foster
}

To cite: Kotecha $A$,

Bonstein $\mathrm{K}$, Cable R, et al. Qualitative investigation of patients' experience of a glaucoma virtual clinic in a specialist ophthalmic hospital in London, UK. BMJ Open 2015;5:e009463.

doi:10.1136/bmjopen-2015009463

- Prepublication history for this paper is available online. To view these files please visit the journal online (http://dx.doi.org/10.1136/ bmjopen-2015-009463).

Received 20 July 2015 Revised 28 September 2015 Accepted 17 November 2015

CrossMark

NIHR Biomedical Research Centre for Ophthalmology at Moorfields Eye Hospital NHS Foundation Trust and UCL Institute of Ophthalmology, London, UK

Correspondence to Aachal Kotecha; aachal.kotecha@ucl.ac.uk

\section{ABSTRACT}

Objectives: To explore how patients felt about delivery of care in a novel technician-delivered virtual clinic compared with delivery of care in a doctordelivered model.

Design: A qualitative investigation using one-to-one interviews before and after patients' appointments at either the standard outpatient glaucoma clinic or the new technician-delivered virtual glaucoma clinic (Glaucoma Screening and Stable Monitoring Service, GSMS).

Setting: A glaucoma clinic based in a tertiary ophthalmic specialist hospital in London.

Participants: 43 patients (38 Caucasian, 5 African/ Afro-Caribbean) were interviewed prior to their glaucoma appointment; 38 patients were interviewed between 4 and 6 weeks after their appointment. Consecutive patients were identified from patient reception lists and telephoned prior to their appointment inviting them to participate.

Results: Trust in the patient-provider relationship emerged as a key theme in patients' acceptance of not being seen in a traditional doctor-delivered service. Patients who were well informed regarding their glaucoma status and low risk of progression to sight loss were more accepting of the GSMS. Patients valued the reassurance received through effective communication with their healthcare practitioner at the time of their appointment.

Conclusions: This study suggests that patients are accepting of moving to a model of service delivery whereby the doctor is removed from the consultation as long as they are informed about the status of their condition and reassured by the interaction with staff they meet. This study highlights the importance of patient engagement when introducing new models of service delivery.

\section{BACKGROUND}

Glaucoma is the leading cause of irreversible blindness in the developed world, and increases in prevalence with advancing age. ${ }^{1}$
Strengths and limitations of this study

- This is the first qualitative interview-based study obtaining views from patients regarding how their glaucoma care is delivered, and how they feel about the move to non-doctor-delivered services.

- Interviews were performed on a one-to-one basis before and 1 month after patients' appointments.

- All patients participating in the study had English as their first language and were predominantly of Caucasian ethnicity; thus, they may not reflect the views of the wider glaucoma patient population.

- The study was performed at a single tertiary referral ophthalmic centre in London; thus, geographical differences in patient opinion still need to be explored.

It is a chronic condition which requires lifelong monitoring once diagnosed. The number of new glaucoma suspect referrals into the hospital eye service (HES) is increasing, partly due to the advances in diagnostic technologies used by primary eye care providers. ${ }^{2}$ This, combined with the increasingly ageing population, has led to some hospital eye departments to predict capacity problems in meeting demand for ophthalmology outpatient services. ${ }^{3-5}$

An approach to meeting increasing demands for services is to remove the face-to-face doctor consultation and implement a 'virtual clinic' within the secondary care setting, whereby nurses or ophthalmic technicians collect data from the patient for a consultant ophthalmologist to review at a later time. Glaucoma lends itself to such a model of care as the disease is usually monitored using digital imaging and functional testing devices ${ }^{6}$ that may be administered by 
trained technical staff. There are a number of National Health Services (NHS) departments around the UK (personal communication: Simon Longstaff, Consultant Ophthalmologist Royal Hallamshire Hospital, Sheffield, January 2014; Jane Kingett, Advanced Ophthalmic Practitioner-Glaucoma Service Lead, West of England Eye Unit, February 2014), ${ }^{7-9}$ and independent sector providers ${ }^{10}$ who use this model.

The key factor in the 'virtual clinic' is that it removes the ophthalmologist from the face-to-face patient consultation. The rationale for their implementation within hospitals is that they both improve the patient journey and improve clinic capacity (personal communication, Simon Longstaff, Consultant, Royal Hallamshire Hospital, Sheffield, January 2014).

The Glaucoma Service at Moorfields Eye Hospital, London, opened a virtual clinic (the Glaucoma Screening and Stable Monitoring Service, GSMS) in March 2014. The purpose of this qualitative interviewbased study was to explore how patients felt about their care delivery, and their impressions on moving away from a doctor-delivered care model where they had experience of both. Patients attending both the traditional consultant-delivered outpatient clinics as well as those attending the GSMS were interviewed. For some patients, it was their first visit to the hospital for assessment (whether at GSMS or in a consultant-delivered clinic) following a referral by an optometrist or general practitioner.

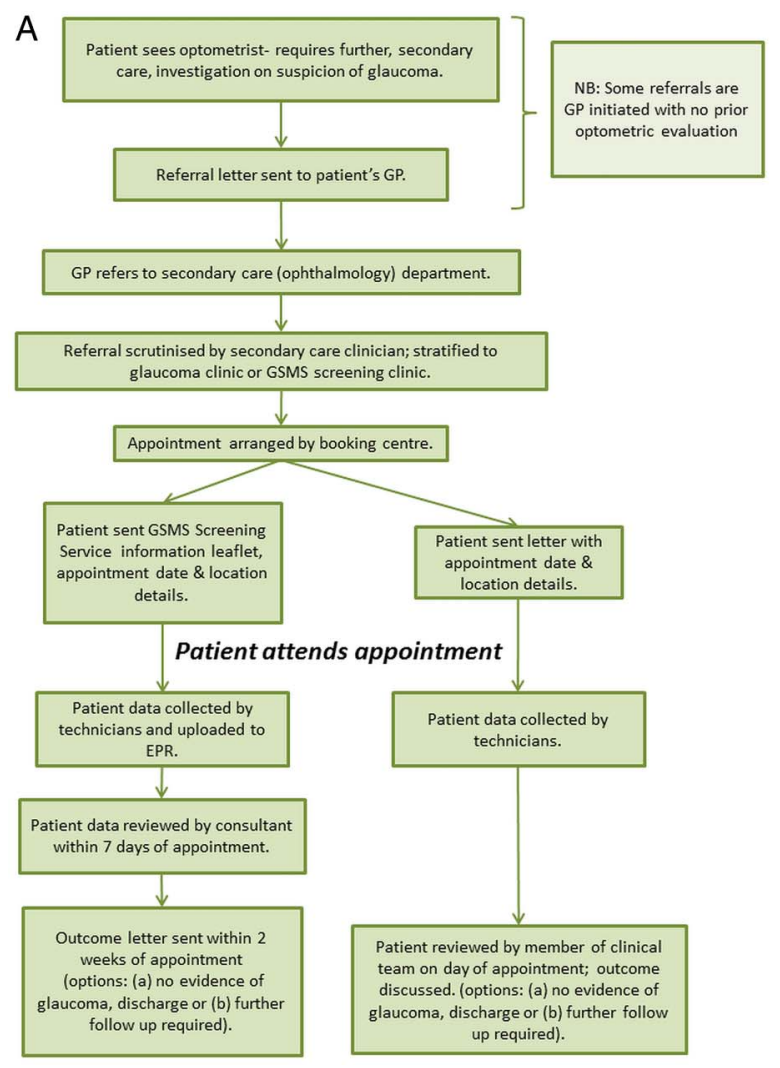

B

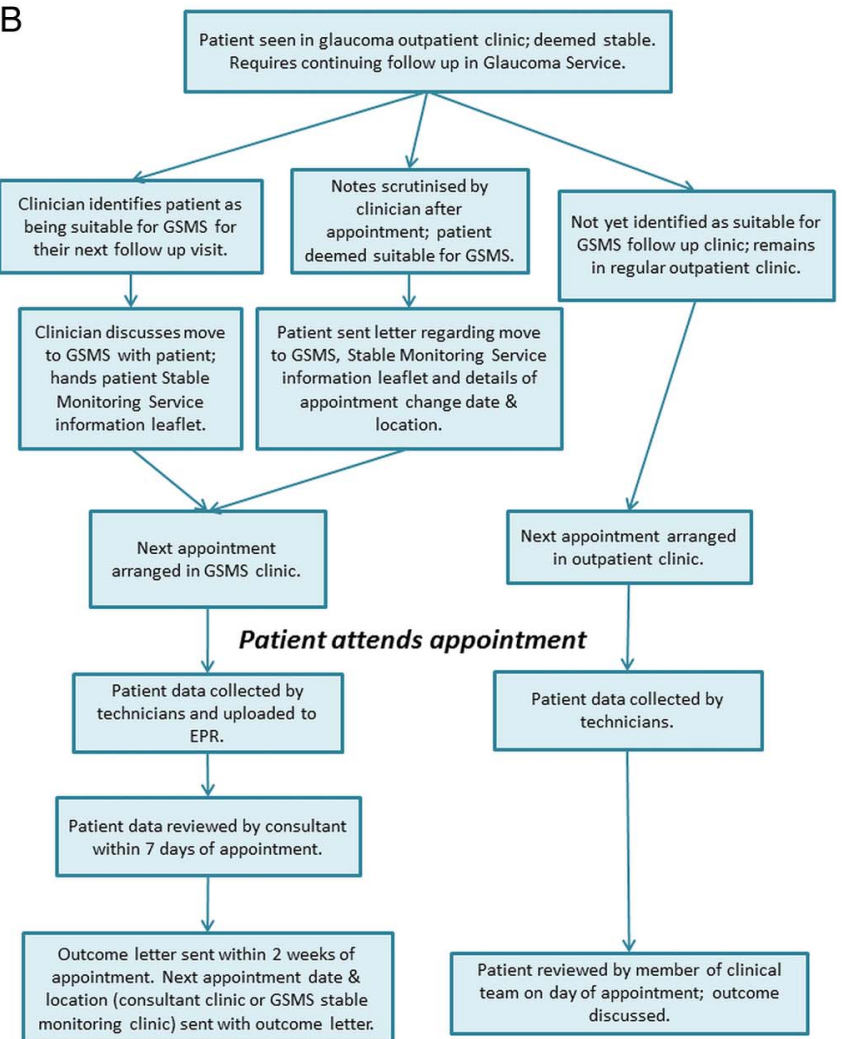

Figure 1 Flow charts illustrating (A) new patient and (B) stable patient journey. GP, general practitioner; GSMS, Glaucoma Screening and Stable Monitoring Service; EPR, electronic patient record.

\section{METHODS}

The GSMS was suitable for low-to-moderate risk, new glaucoma suspect patients, or patients with low-to-moderate stage stable existing glaucoma at low risk of progression, as deemed by their consultant. For new patients, 'low-to-moderate' risk was defined as having up to two of the following risk factors for developing glaucoma: raised intraocular pressure, suspicious looking optic nerves, suspicious visual fields, positive family history. For existing patients, 'low' and 'moderate' disease stages were defined using a modified version of the Canadian Glaucoma Society disease staging guidelines. ${ }^{11}$ The GSMS opened in March 2014. Figure 1 shows a flow diagram describing the new and existing patient journeys through both the GSMS and the glaucoma outpatient clinic.

Semistructured interviews were conducted in the Outpatient Department at Moorfields Eye Hospital NHS Foundation Trust, London, UK, between August and November 2014. Four patient groups were identified:

1. Those attending a new patient appointment in the GSMS,

2. Those attending a new patient appointment in the consultant-delivered glaucoma outpatient service,

3. Those attending a follow-up appointment in the GSMS, and

4. Those attending a follow-up appointment in the consultant-delivered glaucoma outpatient service.

itoring clinic) sect with outcome leter. discussed. 
A sample size of 10-12 patients from each group was proposed as being likely to represent a range of views while also being practical for researchers to analyse. ${ }^{12}$ The sample size fits well with other qualitative research projects into glaucoma patient perceptions. ${ }^{13-15}$

Patients attending the consultant-delivered glaucoma outpatient clinics and the technician-delivered GSMS were invited to participate via a telephone call made between 1 and 5 days prior to their scheduled appointment.

The patient selection process was as follows: reception lists for both types of clinic were printed off in advance. For those attending the GSMS, consecutive patients were telephoned and invited to participate. For those attending a consultant-delivered outpatient appointment, consecutive scheduled patients had their hospital records examined by a clinician (AK) to establish that they were of a similar disease stage/risk as those attending the GSMS. Once identified, patients were telephoned and invited to participate. All invitations were made by the same clinician (AK). Patients were advised that the purpose of the interviews was for a service evaluation project and that they would be interviewed immediately before their clinic appointment and interviewed again approximately 1 month later via telephone. All patients attending the GSMS were new to the clinic-that is, any returning patients had previously attended the regular consultant-delivered outpatient clinic and had no previous experience of the new GSMS clinic.

The project conformed to the tenets of the Declaration of Helsinki and informed consent was taken prior to the start of each interview. Interviews were conducted by one of four people (KB, RC, JCl, JCa) using a predetermined topic guide (figure 2). The topic guide was developed based on some of the common free-text responses to an in-house patient satisfaction feedback form given to patients attending the GSMS in the preceding months, as well as the service managers' interest into how the service was being perceived.

Preappointment interviews took place in a quiet waiting area in the hospital that was out of the earshot of other patients and staff. Patients were advised that the interviewer would take verbatim notes regarding their statements and that all responses would be anonymised. Once notes had been taken, the interviewer would read back their notes to the patient to confirm that they had captured the patient's responses to questions asked. Postappointment interviews were conducted via telephone at a time convenient to the patient. A half hour slot was given for each interview, although interviews were terminated when the end of the topic guide had been reached and/or patients had nothing further to add. The team involved in conducting the interviews was not part of the patients' clinical care team and did not work in the hospital's glaucoma department. All researchers were part of the University College London Biomedical Research Centre (Ophthalmology) Public and Patient Involvement team and were involved and experienced in qualitative research exercises.
The following serves as a topic guide for interview questions:

\section{Pre- appointment interview:}

1. What do you think of the information you've received regarding this appointment?

2. How was the booking process?

3. Who do you expect to see today? What do you expect to happen during your appointment? Do you know why you are here today?

4. What are your impressions of [the hospital]so far?

5. How do/would you feel about not being seen by a doctor today?

\section{Post- appointment interview:}

1. What worked well or didn't work well during your visit to [the hospital]? Were you seen promptly/on time? Did you have to wait long between each test?

2. Did you feel that the staff were professional and courteous? Did you know why you were having various tests performed?

3. Did you feel the staff were well organised?

4. Did you feel safe in the hands of the staff who saw you for your appointment?

5. What did you think about the information you received after all your tests had been done/after your consultation?

6. What aspects of your appointment were you particularly happy with/impressed with?

7. What aspects of your appointment were you not so happy with?

8. How could we improve things?

Figure 2 Interview topic guide.

Demographic data and medical information pertaining to the patient's diagnosis data was also collected.

The study protocol was developed and is reported according to the Consolidated Criteria for Reporting Qualitative Research (COREQ). ${ }^{16}$

\section{Data analysis}

All notes were transcribed to an Excel spreadsheet and analysed by four of the authors (RC, JCl, JCa, AK) using a thematic framework approach. ${ }^{17}$ Transcripts were initially descriptively coded (open-coded) by each member of the analysis team individually, who then met to perform analytical coding during group discussions until consensus agreement was reached. Themes were identified using a thematic analysis approach. ${ }^{17}$

\section{RESULTS}

The demographics of the patient groups are displayed in table 1 .

Figure 3 illustrates the themes and subthemes that emerged from the analysis. Six main subthemes were identified and these will be explored in greater detail, using patient quotes as examples. Patients have been identified as to whether they were new or existing follow-up (FU) patients, whether they attended the virtual (GSMS) or consultant-led clinic, and by their gender ( $\mathrm{M}=$ male, $\mathrm{F}=$ female $)$. 
Table 1 Demographics of patients interviewed

\begin{tabular}{|c|c|c|c|c|}
\hline & $\begin{array}{l}\text { GSMS 'new } \\
\text { patient' }(n=11)\end{array}$ & $\begin{array}{l}\text { Consultant clinic } \\
\text { 'new patient' } \\
(n=10)\end{array}$ & $\begin{array}{l}\text { GSMS 'follow-up } \\
\text { patient' }(n=11)\end{array}$ & $\begin{array}{l}\text { Consultant clinic } \\
\text { 'follow-up patient' } \\
(n=11)\end{array}$ \\
\hline Average age (years) & 63 & 63 & 66 & 72 \\
\hline Age range (years) & $40-80$ & $39-84$ & $43-78$ & $57-83$ \\
\hline Male:female ratio & $6: 5$ & $6: 4$ & $6: 5$ & $4: 7$ \\
\hline Ethnicity & $\begin{array}{l}10 \text { Caucasian } \\
1 \text { African/ } \\
\text { Afro-Caribbean }\end{array}$ & 10 Caucasian & $\begin{array}{l}9 \text { Caucasian } \\
2 \text { African/ } \\
\text { Afro-Caribbean }\end{array}$ & $\begin{array}{l}9 \text { Caucasian } \\
2 \text { African/ } \\
\text { Afro-Caribbean }\end{array}$ \\
\hline $\begin{array}{l}\text { Number of patients where no } \\
\text { postappointment interview was } \\
\text { available }\end{array}$ & 1 & 2 & 1 & 1 \\
\hline
\end{tabular}

Trust

The theme that was at the core of most patients' perceptions regarding moving from a traditional doctor-led service to a 'virtual clinic' was their trust and confidence in the systems and processes of their care pathway.

Existing patients who trusted their clinical care team were more open to being moved into the GSMS:

They know when I should see a doctor. I feel if they think I should see a doctor, they will tell me.-FU GSMS $5, \mathrm{~F}$

Not really concerned[if I do not see a doctor today] as my condition is not currently serious. If I felt condition was deteriorating[I] would be more aware of who I was seeing and would want to see someone correspondingly senior. I wouldn't be particularly concerned if I didn't see a doctor every time.-FU Consultant 2, F

Patients who were less informed regarding the nature and status of their condition or the care processes were less trusting of the new clinic. Similarly, some patients expressed mistrust about the agenda behind the change. As themes began to emerge from the data it became evident that trust was the key factor linking all other themes and subthemes. These will be discussed in further detail below.

\section{Prior information}

Prior information played a key role in patients' perceptions of their eye care within the HES. This was further split into subthemes which pertained to the administrative processes within the pathway and the clinical information they received regarding their condition. This theme encompasses communication, in many forms, of information such as: why they were attending the service, why they had been moved to the GSMS, the stability of their clinical condition in terms of their risk of significant visual loss and the need to see the doctor.

As indicated in figure 1, all patients transferred to the GSMS should have a patient information leaflet
Figure 3 Themes and subthemes identified during the coding process. HCP, healthcare practitioner.

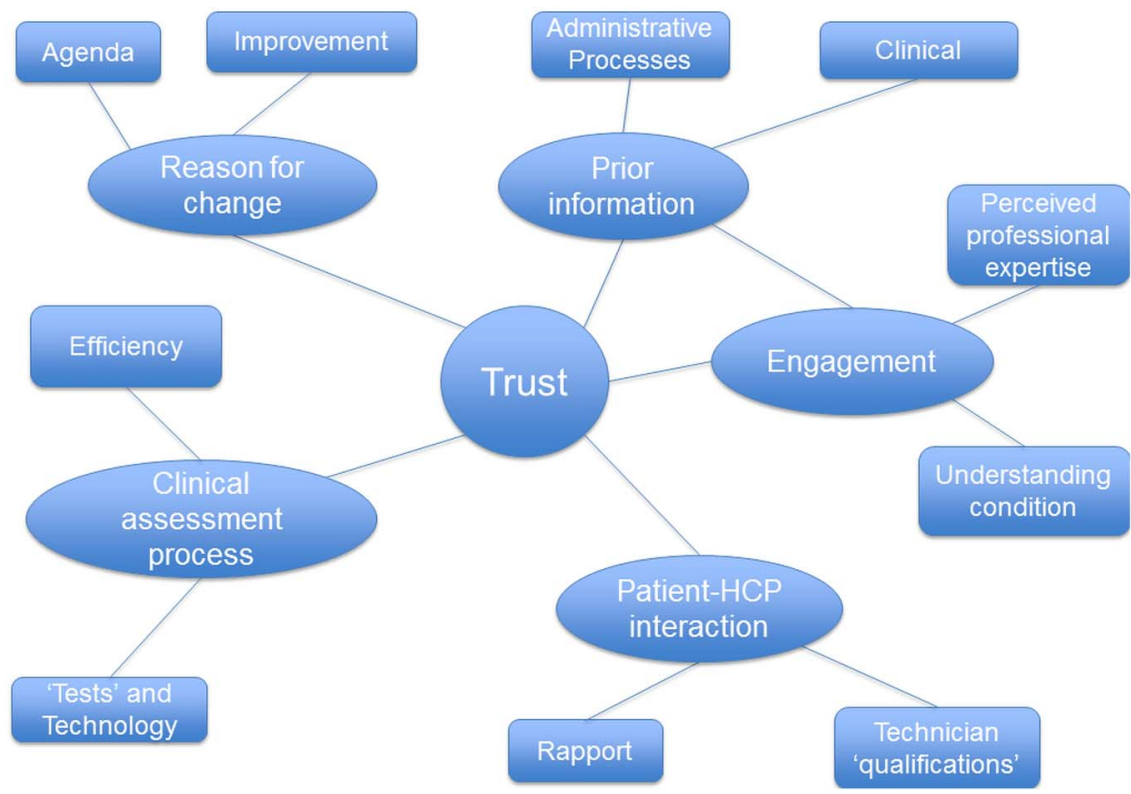


describing the clinic. In addition, patients with existing glaucoma who had been transferred to the GSMS at their previous appointment should have had the move discussed with them at their previous visit.

Patients who were well informed tended to be more accepting of the service they received:

I received a letter explaining that I would have tests done by a technician and that the results would come to my GP in about 2-3 weeks. The technician in the clinic has also explained this when she greeted me...I am happy with the information...[I] just expect to see the technician.-New GSMS 1, F

My optician noticed pressure behind the eye and gave me a letter. I then took the letter to my doctor. I was [sent] a booklet containing directions to the hospital/ clinic and information on what to bring and a letter confirming who my appointment is with. All of the information was very useful. I expect to see a doctor today but [the letter said] it could be someone else.-New Consultant 2, M

However, it was clear that some patients did not get as much information or received confusing information:

There was nothing in the letter about where to go. I asked at the general reception when I arrived and they sent me to clinic 2. When I got there, they didn't think I should be there and sent me to clinic 3. They[clinic 2] didn't think I should be there so I was sent back to clinic 2 and then I was sent over here...I'm not anxious about my appointment so it hasn't been a problem for me but if I had been worried about it, I think it would have been unnerving...-New Consultant 3, M

[I am] a little disappointed[about not seeing a doctor today] as I didn't receive a letter explaining the[virtual] clinic. On arrival, the technician-service was explained well but there is still some disappointment.-New GSMS $6, \mathrm{M}$

In cases where patients had not received prior information regarding the nature of the GSMS, screening 'failure' added to their anxiety:

I am not happy not seeing a doctor[at the virtual clinic visit];[I] have a follow-up appointment in November which is too long to wait!-New GSMS 6, M

This is despite the fact that the reviewing consultant would have chosen an appropriate follow-up interval based on the results of the screening tests.

Prior clinical information pertaining to the reasons for their referral into the clinic also played a significant part in patient experiences. The previous experiences of ophthalmic care, and communication from the care provider, coloured their expectations of the service they would be receiving:
The optician had reported seeing nerve damage and I have a family history of glaucoma.[I am] not concerned [if I do not see a doctor] as long as tests are thorough and promptly evaluated.[I] want to be sure that it is not left too long if treatment is needed.[I] would like a doctor to explain what the optician said as optician made referral but just talked about seeing ' nerve damage', and [I] have had no explanation of possible course of condition or cause.-New GSMS 4, F

In cases where ambiguous clinical information regarding the reasons for referral were given, the lack of doctor contact and screening failure also led to greater anxiety:

[The letter had] no information, no outcome, no explanation. Just a letter saying I 'would benefit from a review in one of our consultant led clinics'. The appointment for this is in 3 months! I am worried in case I need treatment and am having to wait this long for it to start. I have a family history of glaucoma so am anxious about this and would like to know what they found / what the results of my tests were.-New GSMS 4, F

Existing patients booked into the GSMS are stable patients at low risk of progressing to significant visual loss. It might be expected that this would in itself allay patients' concerns about the stability of their condition; however, there were some patients who expressed an anxiety at not seeing a doctor on the day of their GSMS visit:

Would be concerned[if I did not see a doctor] because of the nature of why I'm here.[It is] comforting to see the top person especially for pressure check.-FU Consultant 3, F

I definitely want to see a doctor. That is why you come to a hospital, you come because you have a serious condition.-FU Consultant 5, F.

\section{Engagement}

Another major theme that emerged from the data concerned the level of engagement patients had with their condition and their care. This theme linked closely with 'prior information' since those who were more engaged tended actively to seek out more information, both independently and through the hospital. Some patients trusted that their care team had the professional expertise to decide what was in their best interests, and as such did not wish or feel the need to question the care decisions made. Others appeared not to be informed as to why they were attending for their follow-up appointment or the nature of their condition, but were happy to 'take a back seat' in the process.

All new to me so am just doing as I'm told and have no expectations. Happy to leave it to the staff here to decide who I need to see.-New Consultant 1, F

Other patients valued the consultation and wished to be jointly engaged in discussions of the care decisions made: 
[I] didn't have much explanation of the results. [I] would have preferred to have more information.[I] would like more information of test results at the next appointment. -FU Consultant 6, F

I saw the consultant and felt that I was in the best hands possible. We both came to a decision on my diagnosis and the treatment.-New Consultant 3, M.

\section{Patient/healthcare practitioner interaction}

This theme revolved around the patient/practitioner relationship and how patients valued the rapport that existed within the traditional doctor/patient consultation. Patients viewed the consultation aspect of the visit as a chance to receive 'reassurance' regarding their condition and progress. Those who did not have time to talk to the doctor, or who were unable to build a rapport with the staff they saw at their appointment, were not satisfied with the care they received:

[I had] only a very short time with the consultant. I was disappointed because he hadn't read the notes: he asked about the drops (I am not on drops), and didn't tell me what the pressure was-I had to ask. He said I would have to see just the nurses next time...but I am worried about that.-FU Consultant 8, F

Those who were moved to the virtual clinic were unsure of the roles and responsibilities of the technician, which led to a degree of uncertainty as to what they could or could not ask about their condition:

I did feel safe. My pressure was a bit higher but I wasn't sure about quizzing the technician. He was good though and looked back through the notes to reassure me this had happened before. He also explained that I would be called back if the doctor looking at the results was worried...it was ok...Maybe the technicians could invite the patient to ask questions. Perhaps a bit more interaction with the technicians[could be an improvement].-FU GSMS 2, F

I don't know what a 'technician' is or does, in terms of [their] qualifications[and their] authority. I would have liked information beforehand on what a technician is, because sometimes it can be a derogatory term-'only a technician'.-FU GSMS 1, M

The experience in the virtual clinic was very staff dependent, with some technicians clearly outperforming others in terms of the service they gave:

The staff were very, very professional...They explained everything and told me I wouldn't see a consultant...The way they were working made me feel safe.-FU GSMS 5, F

There was an explanation of a kind but perhaps it is difficult to explain a technical procedure to a non-technical person. [My] only reservation was that there was a slight language barrier as the English was not[the technician's] first language, so[the interaction was] not quite idiomatic.-New GSMS 11, M.

\section{Clinical assessment process}

There were views on the clinical assessment process that covered aspects of waiting times and efficiency, as well as the terminology used and the move towards more technological advances in the assessment process.

Overall, patients expected long waiting and journey times:

Usually takes a long time, there is a long wait at the fields test. Then I see a doctor, it usually takes a long time. Sometimes I have to wait for an hour to see the doctor after the fields test.[This time] there was too long a wait: I was there for 2 hours. And then I only had a very short time with the consultant.-FU Consultant 8, F

I had to wait for quite some time[before I was seen]. I found it hard to find my way through the hospital. I had several tests and had to wait a long time to be seen initially. My visit lasted over 3 hours... The waiting times are too long...It is particularly hard if you are visiting alone. - New Consultant 1, F

Patients moved to the GSMS made positive comments on the organisation of the clinic:

I was happy with more tests being done at this appointment compared with previous appointments with the doctor.[I] felt like my eyes were tested thoroughly as a result of this.-FU GSMS 4, M

[There was] nothing that didn't work well...I was seen on time...I was told what each[test] was for before they did it.[It was] all laid out like an assembly line, straight from one[machine] to the other. Very efficient...It was very thorough, I didn't realise how thorough it would be, it was very reassuring...Good to know there is a part of the NHS which can look after you like that.-New GSMS 3, M

However, some patients expressed an anxiety as to whether their performance would affect test results, which in turn might affect the clinical decisions made by the care team:

I felt the visual fields test wasn't accurate. They ran too many tests too quickly and didn't give my eyes enough time to adjust. The tests weren't explained thoroughly but I was told there was no major worry.-FU Consultant $11, \mathrm{M}$

When I had the peripheral vision test, I wasn't asked a question about my general wellbeing on the day. General wellbeing questions are needed before being tested[as they may affect results].-New Consultant 3, M

Some patients also commented on the modernisation of the hospital, in particular the use of more technology:

[There] was a bit of a concern about not seeing a consultant. ...I have reservations, there is the comfort factor, there is more chance of an error like this...I am 
concerned that the test results won't reach the consultant and that now more records could be lost.-FU GSMS 3, F.

\section{Reason for change}

Patients were diverse in their opinions on the changes to service delivery, with some understanding the need for improvement and appreciating the efficiency of the virtual clinic, with others concerned about the agenda behind the change:

[I am] not happy with[commercial coffee shop], far too expensive...Hospitals shouldn't be depending on commercial money, they should get more government funding. I feel it is important to maintain high standards of qualified expertise and care in the NHS and this may be under threat from new initiatives.-FU Consultant 5, F

I would like to know why the change has been made...is it to save money?-FU GSMS 3, F

Technology coming along can be more efficient than 'human frailties'...I am all in favour of improvements and efficiency, I move with the times.[But] I would prefer to see a doctor...I am a doctor myself[and have] worked in the health service for 40 years. I don't like taking the doctor out of the appointment process.-FU GSMS 6, M.

\section{DISCUSSION}

The findings of this qualitative interview-based study suggest that patient acceptance of new pathways for their glaucoma care centred around trust, which was primarily built through communication between the care provider and the patient. That said, it was evident that some patients implicitly trusted the care teams' decisions based on the reputation of the hospital and the perceived professional expertise that they received.

New patients attending the service had no preconceptions regarding the care pathway, and so their perceptions were very much coloured by the prior information received, either from the hospital or their referring practitioner. Some new patients seen in the virtual clinic expressed an anxiety at not seeing a doctor on the day as they had the perception that their condition was serious, based on the information received by their referring practitioner. Some patients with existing glaucoma felt similar levels of anxiety at removing the doctor from the consultation and moving to a virtual clinic pathway, despite the service only being suitable for stable, low-risk patients.

Glaucoma comprises a wide spectrum of disease ranging from very early disease with low risk of progression to significant sight loss, to those at a more advanced stage with a high risk of progressing to advanced visual loss. It has been shown that those presenting to the UK HES with early disease are at a low risk of progressing to blindness. ${ }^{18}$ Only those patients judged to be at the low risk end of the spectrum would be suitable for the virtual service. Our study revealed that some patients were better informed than others regarding their risk of progression to blindness, and it may be that this lack of knowledge about disease status and risk is due to failings in doctor/patient communication. In their qualitative study evaluating patient perceptions of the visual field test, Glen et $a l^{15}$ also discuss how effective doctor/ patient communication could influence patient responses to follow-up care. Indeed, in our study, those patients who were well informed about their own disease status were very comfortable with the move away from the face-to-face consultation, particularly if it resulted in greater efficiency and less waiting/journey times at their appointment.

It was clear that some patients did not receive sufficient prior information regarding the change to their care pathway, which led to anxiety on arrival at the virtual clinic. It is unclear as to whether patients did not receive or did not read the information sent to them; however, for some there were failings in the administrative processes. Informed patients knew what to expect and were more relaxed as a result. Those who did not have information were much more concerned about the care they would receive and whether it would be to the same standard as that of previous consultant-led visits. Since completing this study, we have developed a patient education video, available on the hospital website, to which patients booked into the service are directed, as well as reiterating to all administrative staff the importance of providing patient information leaflets. We have also emphasised to clinicians working in outpatient clinics the importance of face-to-face communication during the doctor/patient consultation regarding a proposed move to the stable clinic. It is likely that this latter method of communicating change will be the most effective at instilling patient trust and alleviating any patient anxiety with respect to moving from the traditional doctor-led delivery of care.

Reports by the Picker Institute have shown that patients wish to be involved in decisions about their care, ${ }^{19}$ and it has been shown that patients with chronic disease who are more informed about their condition and care needs have better health outcomes. ${ }^{20}$ For some patients, the reputation of the hospital and the previous experience of care within the hospital both contributed to a sense of trust that the decisions made would be in the patient's best interest. For others, the perceived professional expertise of the care providers was enough for them to trust that they would be in a better position to decide what was best for the patient. However, patients who wished to be actively involved in care decisions and who felt that they were not given the opportunity to discuss things with the doctor were less trusting of the care they received at their appointment. Patients are all unique and while there are some who value in-depth discussions regarding how to best manage their condition, for some, too much information can be overwhelming. ${ }^{21}$

While the majority of patients had very positive views about the GSMS, some patients missed aspects of the 
doctor/patient consultation, with some being unsure of the boundaries of the technician/patient relationship. Rapport between the doctor and patient positively impacts on patient satisfaction and patient outcomes. ${ }^{22} 23$ In this study, patients who were able to build up a rapport with their healthcare professional felt reassured and, consequently, satisfied with the care they received, even though they did not receive information on their disease status at their appointment. It is important to remember that technicians delivering the GSMS are not there to replace the doctor, and thus cannot comment on the stability or otherwise of the patient's condition. However, those technicians who were able to effectively communicate with the patient, in terms of what was expected of them and what they should expect to happen, who showed empathy with the patient, as well as showing skill and competence with testing, inspired confidence and trust which contributed to a positive patient experience. Thus, while the technicians will not have the same relationship with the patient as the doctor has had, the way they interact with the patient can still provide the reassurance that the patient needs from the appointment.

As with others' findings, ${ }^{15}$ some patients made comments with respect to the visual field (VF) test and its 'accuracy' at detecting change. The variability and validity of the VF test and the influence of patient performance is widely known among glaucoma specialists ${ }^{24-26}$; thus, results are always interpreted with caution. However, this needs to be communicated to the patient, so that they are reassured that clinicians are fully aware of the impact of patient performance on test results and how this is taken into account particularly when management decisions are made remotely.

Another aspect that raised concern for some patients was what was seen as an over-reliance on technology which was associated with a greater chance of 'lost data'. Previous studies have suggested that older persons view technology in healthcare with more suspicion, in part due to their lack of familiarity with technology. ${ }^{27}$ This suggests that there needs to be better communication regarding how technology can make healthcare provision more efficient, particularly when moving patients to virtual services, in order to increase patient acceptance of these models of service delivery.

The agenda behind the change in service delivery was of some concern to a small number of patients. Rather than being seen as a way to deliver services more efficiently, there were concerns that it was a cost-cutting exercise and would result in reducing the quality of care within the NHS. One patient in particular was very defensive about the NHS and viewed any proposed changes with great suspicion. This view may be in part due to the political climate at the time the study was conducted: the study was performed in a UK election year, and thus there was much media coverage regarding the future of the NHS under different government administrations. However, it also reflects a deeper aspect of how change, as well as the need for change, in service delivery is communicated to patients.

Limitations to the study include the predominantly Caucasian sample which was drawn from patients attending a specialist tertiary referral centre; thus, it is not clear how well the findings may translate to other departments. Furthermore, as postappointment interviews took place approximately 1 month following attendance, there is a possibility that some aspects of the appointment were not recalled and thus not captured by the researchers. Further work is required to assess the acceptability of new models of service delivery in different patient populations.

In conclusion, this study suggests that patients are, on the whole, accepting of moving to a model of service delivery whereby the doctor is removed from the consultation as long as they are informed about the status of their condition and their risk of progression to severe sight loss, and they are reassured by the method of data collection and the interaction with personnel they see at their appointment. Nonetheless, this study highlights the importance of good communication as a way of building trust between the provider and patient, so that they perceive full transparency in how changes will impact on their care without compromise to quality.

Contributors AK was involved in study design, participant recruitment, thematic coding and manuscript preparation. KB was involved in study design, participant interview and manuscript critique. $\mathrm{RC}, \mathrm{JCa}$ and $\mathrm{JCl}$ were involved in participant interview, thematic coding and manuscript critique. PF was involved in study design and manuscript critique.

Funding This study was supported by the Department of Health NIHR Biomedical Research Centre for Ophthalmology at Moorfields Eye Hospital NHS Foundation Trust and UCL Institute of Ophthalmology.

Competing interests None declared.

Provenance and peer review Not commissioned; externally peer reviewed.

Data sharing statement No additional data are available.

Open Access This is an Open Access article distributed in accordance with the Creative Commons Attribution Non Commercial (CC BY-NC 4.0) license, which permits others to distribute, remix, adapt, build upon this work noncommercially, and license their derivative works on different terms, provided the original work is properly cited and the use is non-commercial. See: http:// creativecommons.org/licenses/by-nc/4.0/

\section{REFERENCES}

1. Tham YC, Li X, Wong TY, et al. Global prevalence of glaucoma and projections of glaucoma burden through 2040: a systematic review and meta-analysis. Ophthalmology 2014;121:2081-90.

2. de Silva SR, Riaz Y, Purbrick RM, et al. There is a trend for the diagnosis of glaucoma to be made at an earlier stage in 2010 compared to 2008 in Oxford, United Kingdom. Ophthalmic Physiol Opt 2013;33:179-82.

3. Chalk D, Smith M. Guidelines on glaucoma and the demand for services. Br J Healthc Manage 2013;19:476-81.

4. RNIB. Saving money, losing sight. RNIB campaign report November 2013. http://www.rnib.org.uk/aboutus/mediacentre/mediareleases/ mediareleases2013/Pages/pressrelease14Nov2013.aspx (accessed 21 Jan 2014)

5. Smith R. Our ophthalmology service is "failing", please help! Professional Standards Committee 15 August 2013. http://www.rcophth.ac.uk/news. asp?section=24\&itemid $=1459 \&$ search $=($ accessed 21 Jan 2014).

6. Brusini P. Monitoring glaucoma progression. Prog Brain Res 2008;173:59-73. 
7. Rathod D, Win T, Pickering S, et al. Incorporation of a virtual assessment into a care pathway for initial glaucoma management: feasibility study. Clin Experiment Ophthalmol 2008;36:543-6.

8. Trikha S, Macgregor C, Jeffery M, et al. The Portsmouth-based glaucoma refinement scheme: a role for virtual clinics in the future? Eye (Lond) 2012;26:1288-94.

9. Court JH, Austin MW. Virtual glaucoma clinics: patient acceptance and quality of patient education compared to standard clinics. Clin Ophthalmol 2015;9:745-9.

10. Wright HR, Diamond JP. Service innovation in glaucoma management: using a web-based electronic patient record to facilitate virtual specialist supervision of a shared care glaucoma programme. Br J Ophthalmol 2015;99:313-17.

11. Damji KF, Behki R, Wang L. Canadian perspectives in glaucoma management: setting target intraocular pressure range. Can $J$ Ophthalmol 2003;38:189-97.

12. Guest G, Bunce A, Johnson L. How many interviews are enough? An experiment with data saturation and variability. Field Methods 2006;18:59-82.

13. Green J, Siddall H, Murdoch I. Learning to live with glaucoma: a qualitative study of diagnosis and the impact of sight loss. Soc Sci Med 2002:55:257-67.

14. Prior M, Francis JJ, Azuara-Blanco A, et al. Why do people present late with advanced glaucoma? A qualitative interview study. $\mathrm{Br} J$ Ophthalmol 2013:97:1574-8.

15. Glen FC, Baker H, Crabb DP. A qualitative investigation into patients' views on visual field testing for glaucoma monitoring. BMJ Open 2014;4:e003996.

16. Tong A, Sainsbury P, Craig J. Consolidated criteria for reporting qualitative research (COREQ): a 32-item checklist for interviews and focus groups. Int J Qual Health Care 2007;19:349-57.
17. Braun V, Clarke V. Using thematic analysis in psychology. Qual Res Psychol 2006;3:77-101.

18. Saunders LJ, Russell RA, Kirwan JF, et al. Examining visual field loss in patients in glaucoma clinics during their predicted remaining lifetime. Invest Ophthalmol Vis Sci 2014;55:102-9.

19. Is the NHS getting better or worse?. Picker Institute Europe, 2005. http://www.pickereurope.org/wp-content/uploads/2014/10/ls-theNHS-getting-better-or-worse-....pdf

20. Greene J, Hibbard JH. Why does patient activation matter? An examination of the relationships between patient activation and health-related outcomes. J Gen Intern Med 2012;27: 520-6.

21. Williams SL, Haskard KB, DiMatteo MR. The therapeutic effects of the physician-older patient relationship: effective communication with vulnerable older patients. Clin Interv Aging 2007;2: 453-67.

22. Stewart MA. Effective physician-patient communication and health outcomes: a review. CMAJ 1995;152:1423-33.

23. Goold SD, Lipkin M. The doctor-patient relationship: challenges, opportunities, and strategies. J Gen Intern Med 1999;14(Suppl 1): S26-33.

24. Gardiner SK, Crabb DP. Frequency of testing for detecting visual field progression. Br J Ophthalmol 2002;86:560-4.

25. Chauhan BC, Garway-Heath DF, Goñi FJ, et al. Practical recommendations for measuring rates of visual field change in glaucoma. Br J Ophthalmol 2008;92:569-73.

26. Crabb DP, Garway-Heath DF. Intervals between visual field tests when monitoring the glaucomatous patient: wait-and-see approach Invest Ophthalmol Vis Sci 2012;53:2770-6.

27. Or CKL, Karsh B-T. A systematic review of patient acceptance of consumer health information technology. J Am Med Inform Assoc 2009;16:550-60. 